\title{
REFLEXÕES PARA UM JUDICIÁRIO SOCIOAMBIENTALMENTE RESPONSÁVEL
}

\author{
REFLECTION FOR A RESPONSIBLE SOCIAL \\ AND ENVIRONMENTAL JUDICIARY
}

\section{Por Claudia Maria Barbosa*}

RESUMO: O artigo parte de determinadas concepções sobre desenvolvimento e sustentabilidade, desde um enfoque crítico que as considera insuficientes, defendendo a necessidade da existência de um poder judiciário socioambientalmente responsável devendo tal noção guiar o seu papel e as sua ações. Analisa, ainda, as referências legais de direito público, as referencias teóricas que fundamentam a sustentabilidade e os parâmetros constitucionais brasileiros que impedem a construção de uma sociedade digna. Um poder judiciário socioambientalmente responsável considera as concepções de direito e de bens socioambientais e defende um novo paradigma de desenvolvimento capaz de promover não somente a sustentabilidade estritamente ambiental, mas também a sustentabilidade social. Nesse sentido, propõe-se a reformulação dos conceitos de propriedade e liberdade para conceber novos direitos coletivos não suscetíveis de valorização econômica, nem de apropriação por parte de um patrimônio individual e, assim, defende-se a obrigação do poder judiciário de proteger os bens sócio-ambientais essenciais à permanência da vida de todas as espécies (biodiversidade) e de todas as culturas humanas (sócio-diversidade).

PALAVRAS-CHAVE: Poder Judiciário; direitos coletivos e bens socioambientais.

* Prof. Titular de Direito Constitucional do Curso de Direito da PUCPR e vice-presidente do instituto Brasileiro de Administração do Sistema Judiciário-IBRAJUS.
RESUMEN: El artículo parte de determinadas concepciones sobre desarrollo y sustentabilidad, pero a partir de un enfoque crítica al considerarlas insuficientes; defendiendo, por su vez, la necesidad de existencia de un Poder Judicial socioambientalmente responsable, y considerando que esta noción debería ser la guía de su rol y de sus acciones. El artículo analiza, por su vez, referencias legales de Derecho Público así como las referencias teóricas que fundamentan la sustentación y los parámetros constitucionales brasileros que impiden la construcción de una sociedad digna. Un Poder Judicial socioambientalmente responsable considera concepciones de derecho y de bienes socioambientales y defiende un nuevo paradigma de desarrollo que debería promover no sólo la sustentación estrictamente ambiental, sino también la sustentación social. En ese sentido, propone la reformulación de los conceptos de propiedad y de libertad para concebir nuevos derechos colectivos, no susceptibles de valorización económica ni de apropiación por parte de un patrimonio individual. Defiende, asimismo, la obligación por parte del Poder Judicial de proteger los llamados bienes socio-ambientales, esenciales para la permanencia de la vida de todas las especies (biodiversidad) y de todas las culturas humanas (socio-diversidad).

PALABRAS CLAVE: Poder Judiciário; derechos colectivos e bienes socioambientales. 


\section{INTRODUÇÃO}

O aparente consenso existente em torno da necessidade da construção de uma sociedade brasileira digna, justa e solidária não sobrevive a diferentes abordagens sobre o tema realizadas por organismos multilaterais como o Banco Mundial, organização internacionais como a Organização das Nações Unidas (ONU), e por Organizações Não-Governamentais como o Instituto Socioambiental (ISA) no Brasil, além das pesquisas realizadas em Universidades brasileiras e estrangeiras. Além de distintos objetivos, o assunto permite enfoques diversos e implica a definição de prioridades que diferem conforme partam de premissas políticas distintas e marcos teóricos diferentes. Em comum apenas a preferência por uma análise transdisciplinar.

O presente estudo será desenvolvido a partir dos conceitos de desenvolvimento e sustentabilidade, os quais fornecerão alguns dos pressupostos teórico-políticos que possibilitam a abordagem da proposta de um Judiciário Sustentável, que delineia premissas que possam informar as discussões em torno de um sistema judiciário apto a auxiliar na consecução de uma sociedade digna, capaz de enfrentar os desafios que lhe vêm sendo impostos no III Milênio que acaba de iniciar-se.

\section{MARCOS JURÍDICOS DO DESENVOLVIMENTO E DA SUSTENTABILIDADE}

\subsection{Direito Internacional Público}

A Convenção Americana de Direitos Humanos, conhecida como Pacto de São José da Costa Rica, fez referência em seu
Artigo 26 ao Desenvolvimento Progressivo, vinculando-o "à plena efetividade dos direitos que decorrem das normas econômicas, sociais e sobre educação, ciência e cultura..."1

O Pacto Internacional dos Direitos Civil e Políticos ${ }^{2}$ assegura a todos os povos o

direito ao desenvolvimento econômico, social e cultural, advertindo no Artigo $1^{\circ}$, item 2 que "em caso algum poderá um povo ser privado de seus próprios meios de subsistência", mesmo texto repetido no Pacto Internacional dos Direitos Econômicos, Sociais e Culturais ${ }^{3}$.

Embora o Pacto da Costa Rica, já citado, tenha integrado o ordenamento jurídico em 1992, estabeleceu apenas em 1998, por meio do Decreto Legislativo n. ${ }^{\circ} 89$, a jurisdição obrigatória da Corte Interamericana de Direitos do Homem para os casos de desrespeito aos Direitos Humanos, neles incluídos o direito ao desenvolvimento.

Iniciativas isoladas sobre a degradação ambiental são datadas dos anos sessenta, mas o marco do direito público internacional a respeito do tema é a Conferência sobre o Meio Ambiente, promovida pela ONU em Estocolmo em 1972 ${ }^{4}$. Neste mesmo ano,

1 A Convenção Americana de Direitos Humanos foi celebrada em 1969, entrou em vigor em 1978 e, no Brasil, passou a integrar o ordenamento jurídico a partir de 1992, por meio do Decreto Legislativo n. 27, de 26 de maio de 1992.

2 O Pacto Internacional dos Direitos Civis e Políticos data de 1966 e foi ratificado por meio do Decreto 592, de 06 de julho de 1992.

Pacto Internacional dos Direitos Econômicos, Sociais e Culturais data de 1966 e foi ratificado pelo Brasil por meio de Decreto Legislativo n. ${ }^{\circ} 226$, de 12.12.1991.

4 A Declaração de Estocolmo sobre o Meio Ambiente Humano, datada de 1972, pode ser acessada no endereço http://www.dhnet.org.br/direitos/sip/onu/ doc/estoc72.htm. 
Dennis MEADOWS (1973) e pesquisadores do "Clube de Roma" publicaram o estudo denominado Limites do Crescimento, no qual advertem para o fato de que a manutenção dos níveis de gradação ambiental então existentes, em 100 anos comprometeria o desenvolvimento humano.

Um ano depois o canadense Maurice Strong lançou o conceito de ecodesenvolvimento ${ }^{5}$ cujos princípios foram formulados por Ignacy Sachs. SACHS (1986) indica seis caminhos do desenvolvimento: satisfação das necessidades básicas; solidariedade com as gerações futuras; participação da população envolvida; preservação dos recursos naturais e do meio ambiente; elaboração de um sistema social que garanta emprego, segurança social e respeito a outras culturas; programas de educação.

Segunda aponta Taís MARTINS (2008), uma outra importante contribuição à compreensão das relações entre desenvolvimento e meio ambiente foi estabelecida pela Declaração da Cocoyok, das Nações Unidas, a qual atribuiu à pobreza a causa da explosão demográfica que gerava a destruição de recursos naturais, e relacionou essa mesma destruição ao alto padrão de consumo dos países ricos. Este documento foi complementado pelo Relatório DagHammarskjöld, no que se afirma que as potências coloniais concentraram as melhores terras das colônias nas mãos de uma minoria, forçando a população pobre a usar outros

5 Maurice Strong era diretor executivo do PNUMA Programa das Nações Unidas para o Meio Ambiente e em 1973 propôs o conceito de ecodesenvolvimento, depois ampliado por Ignacy Sachs. Para saber mais a respeito de ecodesenvolvimento, ver International Institute for Sustainable Development (IISD): $<$ http://iisd1.iisd.ca/>. Acesso em 26 de junho de 2008. solos, promovendo a devastação ambiental. Comum a ambos os relatórios é a exigência de mudanças nas estruturas de propriedade do campo e a rejeição pelos governos dos países industrializados.

Em dezembro de 1986 aprovou-se a Declaração sobre o Direito ao Desenvolvimento, ${ }^{6}$ que em seu Artigo $1^{\circ}$ estabeleceu: "O direito ao desenvolvimento é um direito humano inalienável, em virtude do qual toda pessoa e todos os povos estão habilitados a participar do desenvolvimento econômico, social, cultural e político, a ele contribuir e dele desfrutar, no qual todos os direitos humanos e liberdades fundamentais possam ser plenamente realizados". A mesma noção foi confirmada na Conferência de Viena em 1993, quando foi aprovada consensualmente.

Pouco tempo depois a ONU publicou o documento intitulado Nosso Futuro Comum, resultado dos trabalhos desenvolvidos pela Comissão Mundial da ONU sobre o Meio Ambiente e Desenvolvimento (UNCED), presidida por Gro Harlem Brundtland e Mansour Khalid, o qual define: "desenvolvimento sustentável é desenvolvimento que satisfaz as necessidades do presente sem comprometer a capacidade de as futuras gerações satisfazerem suas próprias necessidades”. Neste conceito externou-se pela primeira vez uma concepção de risco.

Em 1992 realizou-se no Rio de Janeiro a ECO-927 , Conferência Mundial sobre

6 A Declaração sobre o Direito ao Desenvolvimento dói aprovada pela Resolução n ${ }^{\circ}$ 41/128 da Assembléia Geral das Nações Unidas, de 4 de dezembro de 1986.

Conferência das Nações Unidas para o Meio Ambiente e o Desenvolvimento (CNUMAD), realizada entre 3 a 14 de junho de 1992, no Rio de Janeiro, Brasil. 
Meio Ambiente e Desenvolvimento, na qual foi editada a Agenda $21^{8}$ que procura construir um consenso na atuação dos Estados visando ao desenvolvimento sustentável ${ }^{9}$. Ambos os documentos ressaltam a necessidade de tratamento conjunto dos problemas de desenvolvimento socioeconômico e meio ambiente.

Um ano depois, em 1993, realizou-e em Viena a segunda grande Conferência Mundial de Direitos Humanos, a qual reafirmou em seu Artigo 10 o que já havia constado da Declaração de Iran, de 1968: o direito ao desenvolvimento é um direito humano fundamental inalienável. O documento persa de 25 anos antes ia, contudo, mais além, porque determinava em seu parágrafo 13 que "os direitos humanos e as liberdades fundamentais são indivisíveis, a realização plena dos direitos civis e políticos sem o gozo dos direitos econômicos, sociais e culturais, é impossível". (SILVA JÚNIOR, 2008).

Em Cairo, no ano de 1994, a Conferência Internacional sobre população e Desenvolvimento reafirmou o direito ao desenvolvimento como um direito inalienável. A este reunião seguiu-se no ano de 1995, em

8 Agenda 21 é o principal documento produzido na ECO-92. Trata-se de é um programa de ação que viabiliza o novo padrão de desenvolvimento ambientalmente racional. Ele concilia métodos de proteção ambiental, justiça social e eficiência econômica. Está documento está estruturado em quatro seções subdivididas num total de 40 capítulos temáticos

9 A Agenda 21 consagrou sobre o tema dois princípios: "Princípio $3^{\circ} \mathrm{O}$ direito ao desenvolvimento deve ser exercido de modo a permitir que sejam atendidas eqüitativamente as necessidades de gerações presentes e futuras. Princípio $4^{\circ}$ Para alcançar o desenvolvimento sustentável, a proteção ambiental deve constituir parte integrante do processo de desenvolvimento, e não pode ser considerada isoladamente deste"
Copenhague a Reunião de Cúpula de Copenhague para o Desenvolvimento Social que reiterou o conceito de desenvolvimento sustentável, abrangendo numa estratégia integrada o desenvolvimento econômico, social, ambiental e cultural.

De lá para cá consolidou-se, pelo menos do ponto de vista dos documentos internacionais, a visão do desenvolvimento como um conceito que deve ser integrado às questões socioeconômicas e culturais dos povos.

\subsection{Constituição Brasileira}

A Constituição Brasileira consagrou em seu Artigo $1^{\circ}$, inciso III a dignidade da pessoa humana como um dos fundamentos do Estado Democrático de Direito; definiu a construção de uma sociedade livre, justa e solidária como objetivos fundamentais da República (Artigo $\left.3^{\circ}, \mathrm{I}\right)$; determinou, a teor do disposto no Artigo 170, que a ordem econômica deve assegurar a todos, existência digna; estabeleceu o bem-estar e a justiça social como objetivos da ordem social, conforme disposição clara do Artigo 193, caput; e determinou que "todos têm direito ao meio ambiente ecologicamente equilibrado, impondo-se ao Poder Público e à coletividade o dever de defendê-lo e preservá-lo para as presentes e futuras gerações", a teor do constante em seu Artigo 225.

Todos os dispositivos impõem, à sociedade como um todo e ao poder público em particular, diretrizes que devem balizar as suas ações, de forma a alcançar dignidade, justiça social, proteção e defesa do meio ambiente para a geração presente e também para as que virão. São princípios que, à luz da moderna teoria constitucional, possuem 
juridicidade e imperatividade, mesmo que às vezes relativizados por técnicas interpretativas como a reserva do possível e a ponderação.

Também a Carta Magna estabeleceu o Executivo, Legislativo e Judiciário como Poderes da União (Artigo $2^{\circ}$ ), atribuiu ao Supremo Tribunal Federal a precípua guarda da Constituição (Artigo 102), e aos demais órgãos do Judiciário determinou o respeito à Constituição, exercido nos limites das respectivas competências constitucionalmente estabelecidas, incumbindo-lhes desta forma a tarefa de concretizar a Constituição.

Pelo exposto, observa-se que o desenvolvimento em sua acepção mais ampla e a dignidade humana são objetivos prioritários da sociedade brasileira, e nesta condição devem ser perseguidos pelas ações governamentais, pela sociedade civil, e também pelo Poder Judiciário, a quem cabe zelar pelo respeito e, por consequiência, pela observância das normas constitucionais. Lutar por eles não é, ou não deveria ser, uma opção política, mas uma obrigação constitucional. É nesse contexto que o papel do sistema de justiça, e do Poder Judiciário especificamente, torna-se essencial na realização do chamado Estado Democrático de Direito.

\section{I N D I C A D O R E S D E D ES E N V O L V I M E N T O E SUSTENTABILIDADE}

O conceito de desenvolvimento encontra eco na sociedade a partir da obra de Rostow $^{10}$ que "recuperando o darwinismo social, se

${ }^{10}$ Rostow, W.W. Etapas do desenvolvimento econômico. Rio de Janeiro: Zahar. 1971. baseia na idéia de sucessão evolutiva de estágios, onde tal qual na natureza, as sociedades humanas evoluiriam de formas inferiores para superiores. Nesta hipótese, parte-se de um modelo de sociedade rudimentar culminando no modelo da civilização ocidental industrializada de consumo, considerada única e universal" (LAYARARGUES, 1997, p. 1).

Até os anos 70 crescimento e desenvolvimento eram geralmente entendidos como termos correlatos. Da metade dos anos 70 para frente iniciou-se, como se pode perceber dos diferentes documentos internacionais, a construção de um conceito mais amplo de desenvolvimento que levasse em conta não apenas os índices econômicos, mas outras variáveis sociais como nível educacional, taxa de natalidade e mortalidade infantil, confiança nas instituições públicas, entre outros. Desta ação caminhou-se para uma concepção de desenvolvimento sustentável como um processo multidisciplinar integrado econômico, social, ambiental e cultural.

Embora muitas vezes as diferenças sociais e econômicas entre países em diferentes estágios de desenvolvimento sejam facilmente perceptíveis, mensurá-las não é uma tarefa fácil. A falta de indicadores confiáveis pode dificultar ou impedir a verificação do efetivo cumprimento dos objetivos da sociedade brasileira na atuação individual ou conjunta de seus atores, públicos ou privados.

Para superar essa dificuldade elegem-se variáveis, criam-se padrões e constroem-se índices por meio dos quais se possam estabelecer comparações seguras entre países distintos. A proposição e construção desses índices, contudo, decorrem de opções políticas, 
que ficam camufladas sob os resultados estatísticos e frios, freqüentemente apontados como absolutos pelos indicadores utilizados.

É nesse processo que a complexidade socioeconômica de diferentes países desaparece, apresentando-se em seu lugar os resultados individuais dos seus Produto Interno Bruto (PIB), índice que expressa economicamente a soma de todos os bens e serviços finais produzidos em uma determinada região, durante um período determinado, e usado frequentemente como uma medida de bem estar material, razão pela qual se costuma apontar politicamente suas cifras como índice de crescimento de um país. Como índice econômico é, ressalte-se, inapropriado para expressar as condições sociais em que vive um determinado povo. Apesar disso, continua a ser utilizado para avaliar o grau de desenvolvimento de um país, reduzindo esse conceito a uma perspectiva econômica, distante da concepção integral definida pela ONU.

As limitações desse parâmetro vêm ensejando sua substituição por índices mais completos, em busca de uma fórmula que seja capaz de traduzir a realidade socioeconômica de um país em números, considerando variáveis mais amplas que superem as restrições da análise meramente econômica. Com esta finalidade foram propostos o IDH (Índice de Desenvolvimento Humano); o coeficiente de Gini; o IBES (Índice de Bemestar Social Econômico Sustentável ou Index of Sustainable Welfare - ISEW), proposto por Herman Daly e John Cobb para mensurar uma medida de bem-estar agregado, em que o fluxo de produtos e serviços provenientes de todas as fontes, e não apenas do conjunto de atividades que delimitam a fronteira de produção, mostrasse-se relevante para o bemestar econômico de uma nação; e a versão mais atual deste, denominado IPG (Índice de Progresso Genuíno), por enquanto utilizado em pequena escala.

Importante indicador para calcular a desigualdade de distribuição de renda, o coeficiente de Gini, criado em 1912 pelo italiano Corrado Gini, presta-se para calcular a desigualdade de distribuição de renda. Ele consiste em um número entre 0 e 1 , sendo que 0 corresponde à completa igualdade de renda (onde todos têm a mesma renda) e 1 corresponde à completa desigualdade (na qual uma pessoa tem toda a renda, e as demais nada têm). O índice de Gini é o coeficiente expresso em pontos percentuais, e é igual ao coeficiente multiplicado por 100.

A ONU, ciente das deficiências de análises baseadas no PIB, passou a adotar o IDH, Índice de Desenvolvimento Humano, desenvolvido por Mahbub ul Haq ${ }^{11}$ com a colaboração da economista indicado, prêmio Nobel de economia, Amartya Sen ${ }^{12}$. O IDH

${ }^{11}$ Mahbul ul Haq nesceu em 1934 e faleceu em 1998. Foi um influente e renomado economista paquistanês, um dos desenvoltores da Teoria do Desenvolvimento Humano. Formulou junto com Amartya Zen o Indice de Desenvolvimnto Humano (IDH), um dos mais influentes índices, que tem sido usado pelo ONU desde os anos 90 para medir o grau de desenvolvimento humano de um país. Disponível em http://hdr.undp.org

12 Amartya Sem é um economista indiano nascido em 1933. Ganhador do prêmio Nobel de economia de 1998 por sua contribuição para a teoria da decisão e do welfare state. Sua maior contribuição é mostrar que o desenvolvimento de um país está essencialmente ligado às oportunidades que ele oferece à população de fazer escolhas e exercer sua cidadania. E isso inclui não apenas a garantia dos direitos sociais básicos, como saúde e educação, como também segurança, liberdade, habitação e cultura. 
propugna por um conceito de desenvolvimento humano resultante da combinação de três dimensões: longevidade, educação e renda, medida em PIB per capita expressa em dólares PPC (paridade do poder de compra).

Esses indicadores têm em comum o fato de levar em conta para sua composição variáveis sociais e econômicas que, combinadas de maneira peculiar por cada indicador, buscam traduzir objetivamente a realidade socioeconômica de um país, bem como seu grau de desenvolvimento, de forma a permitir análises comparativas "seguras". Cada indicador reflete uma concepção específica de desenvolvimento que deveria estar em consonância com a noção de desenvolvimento sustentável, mas isso não ocorre por diversas razões: em primeiro lugar, o conceito é aberto e não há uma fórmula mágica que possa expressá-lo; em segundo lugar, a complexidade social é difícil de ser expressa em índices numéricos; em terceiro, as variáveis que compõem um índice expressam uma concepção pré-determinada de desenvolvimento que pode mascarar determinados resultados positivos e fortalecer outros negativos, contaminando o resultado final.

De fato, embora mais abrangente que o PIB, os outros índices já citados, além do próprio IDH utilizado pela ONU, são parâmetros ainda incapazes de captar os movimentos em torno do que o relatório Brauntland definiu com o desenvolvimento sustentável, porque são imprestáveis para mensurar o grau de proteção ambiental e preservação dos recursos naturais nãorenováveis, requisitos implícitos no conceito que trata da necessidade de preservar o futuro desta e das próximas gerações; incapazes de expressar o custo social da pobreza; ineficientes para definir políticas públicas voltadas à realização das diretrizes constitucionais brasileiras de uma sociedade livre, justa e solidária.

\section{NOVOS PARADIGMAS PARA A SUSTENTABILIDADE}

Baseados em diferentes combinações dos aspectos econômico, social, ambiental e cultural, pressupostos do conceito de desenvolvimento sustentável, há diferentes movimentos que desde os anos 70 propugnam por uma transformação social assentada sobre paradigmas não dominantes, que têm em comum o fato de serem contrários à noção ainda hegemônica de desenvolvimento associado diretamente ao crescimento econômico e ao aumento do consumo. Embora não esteja disponível um parâmetro numérico aceito em larga escala para indicar o processo desenvolvimentista buscado por esses movimentos, todos contrariam o crescimento econômico como padrão de desenvolvimento, refutam a concepção de desenvolvimento social expressa pelo IDH e buscam a sustentabilidade. Análises sociais mais recentes enfatizam também a tecnologia e a informação como elementos que têm o potencial de mudar a sociedade dita moderna.

Neste campo podem-se incluir o ecodesenvolvimento (SACKS), a ecologia profunda $^{13}$ (NAESS) e o socioambientalismo ${ }^{14}$ (SOUZA FILHO), os quais dividem a tentativa

${ }^{13}$ Para entender mais sobre ecologia profunda, ver http://www.deepecology.org/movement.htm

${ }^{14}$ Para entender mais sobre socioambientalismo, ver SANTILLI, Juliana. Socioambientalismo e novos direitos: proteção jurídica à diversidade biolígica e cultural. São Paulo: Petrópolis, 2005. 
de explicar os movimentos da sociedade no século XXI com a chamada modernidade reflexiva (GIDDENS, ECK, LASH), a sociedade do risco (BECK), pós-modernidade (SANTOS), modernidade líquida (BAUMAN), entre outros.

Desenvolvimento sustentável e sustentabilidade podem ser conceitos análogos, mas não são sinônimos. Desenvolvimento sustentável foi traduzido de forma simples e brilhante no relatório coordenado por Gro Bruntland ${ }^{15}$ como aquele "que atende às necessidades das gerações presentes sem comprometer a possibilidade das gerações futuras atenderem às suas próprias necessidades". É um conceito bastante amplo e aberto que tem sido muito utilizado nas ações voltadas à necessidade da proteção ambiental e na preservação dos recursos naturais. A sustentabilidade adjetiva, qualifica o conceito que neste contexto assumirá diferentes faces conforme se defina sustentabilidade.

Sachs buscando explicar o ecodesenvolvimento descreve cinco dimensões para a sustentabilidade: social, econômico, ecológica, espacial e cultural. Cada uma dessas dimensões comporta ações que se voltam à realização do bem-estar dos povos. É da combinação dessas dimensões que se podem explicar vários movimentos que buscam compreender o "nosso tempo" e construir o "tempo futuro".

O socioambientalismo surgiu no Brasil, por volta da década de 1980, a partir das

15 O relatório Bruntland é o documento intitulado Nosso Futuro Comum, publicado em 1987 e coordenado pela então primeira-ministra da Noruega, Gro Harlem Brundland, que chefiou a Comissão Mundial sobre o Meio-Ambiente e Desenvolvimento da ONU. articulações políticas entre os movimentos sociais e ambientalistas, tornadas possíveis devido ao processo de democratização do país no início desta década. Segundo relata Juliana Santilli,

desenvolveu-se com base na concepção de que, em um país pobre e com tantas desigualdades sociais, um novo paradigma de desenvolvimento deve promover não só a sustentabilidade estritamente ambiental ou, seja, a sustentabilidade de espécies, ecossistemas e processos ecológicos - como também a sustentabilidade social - ou seja, deve contribuir também para a redução da pobreza e das desigualdades sociais e promover valores como justiça social e equidade. Além disso, no novo paradigma de desenvolvimento preconizado pelo socioambientalismo deve promover e valorizar a diversidade cultural e a consolidação do processo democrático no país, com ampla participação social na gestão ambiental (SANTILLI, 2005, p. 34).

E segue afirmando que

o socioambientalismo nasceu, portanto, baseado no pressuposto de que as políticas públicas ambientais só teriam eficácia social e sustentabilidade política se incluíssem as comunidades locais e promovessem uma repartição socialmente justa e eqüitativa dos benefícios derivados da exploração dos recursos naturais (2005, p. 35).

Esse movimento busca conciliar as dimensões de sustentabilidade de que fala Sachs, defendendo a necessidade de construção de um modelo de desenvolvimento que preserva os recursos naturais, protege o meio ambiente, garante a diversidade cultural, assegura os direitos das ditas minorias, promove e distribui justiça social, possibilita condições de vida digna, promove valores democráticos e fortalece a cidadania.

O modelo propugnado, paradoxalmente, parecer ser ao mesmo tempo ideal e, portanto, inatingível, e universal, mas não é nem uma 
nem outra coisa. O desenvolvimento socioambiental tem objetivos interconectados, de maneira que a realização de um facilita o alcance de outro, e assim por diante. Esses objetivos demandam metas e ações que a sociedade deve buscar, definindo-se nessa busca prioridades, como acontece com qualquer projeto de ação voltado a um específico objetivo.

Também não corresponde a um valor universal porque inverte, quando necessário, a lógica econômica que norteia os modelos de desenvolvimento hegemônicos, priorizando as dimensões ecológica e social, necessárias para a preservação da vida digna, o que implica o reconhecimento de duas prioridades: preservação dos recursos naturais, sem os quais a vida será limitada, e realização da dignidade humana, vista desde uma perspectiva mais ampla que supere a noção tradicional de dignidade como um atributo individual.

O termo "socioambiental" não está consagrado na Constituição, mas a previsão constitucional de construção de uma sociedade livre, justa e solidária, fundada na dignidade humana e erigida com a preservação ambiental permitem inequivocamente vislumbrá-lo. A tutela dos direitos socioambientais, ao contrário, tem clara guarida constitucional expressa na obrigatoriedade do poder público de proteger o patrimônio histórico, cultural e artístico (art. 23); na proteção estatal à cultura e suas manifestações (art. 215), ao meioambiente (art. 225) e à organização social indígena (art. 231), entre outros. Essa tutela volta-se à proteção dos chamados bens socioambientais, definidos por Carlos Marés como todos aqueles que adquirem essencialidade para a manutenção da vida de todas as espécies (biodiversidade) e de todas as culturas humanas (sociodiversidade). Assim, os bens ambientais podem ser naturais ou culturais, ou se melhor podemos dizer, a razão da preservação há de ser predominantemente natural ou cultural se tem como finalidade a bio ou a sociodiversidade, ou a ambos, numa interação necessária entre o ser humano e o ambiente em que vive. (2002, p. 38)

Para a compreensão exata do que sejam direitos socioambientais, adverte Marés,

é necessário partir do conceito de direitos coletivos, inscrito na Constituição. Entretanto, para a compreensão dos direitos coletivos, a leitura da Constituição não é suficiente, é necessário entendê-los em sua plenitude e em cotejo com o direito individual, porque a Constituição reconheceu a existência de direitos coletivos ao lado dos individuais, quer dizer, não os excluiu nem aboliu. Mesmo assim, do ponto de vista jurídico, isto é uma ruptura com a modernidade que apenas concebia direitos individuais, material ou imaterialmente apropriáveis e um patrimônio individual economicamente valorável. Os direitos coletivos, contrariando este fundamento da modernidade, não são valoráveis economicamente nem poder ser apropriados a um patrimônio individual. (2002, p. 26)

4. D I RETRIZES PARA U M J U D I C I Á R I O E F I C A Z EM UMA S OCIEDA D E S O C I O A M B IEN TA M EN TE DESENVOLVIDA

A percepção de ineficácia estrutural do sistema judiciário não é uma exclusividade brasileira, e são vários os fatores apontados: culturais, econômicos, sociais, jurídicos, entre outras. Novidade no Brasil são as propostas para mudar essa realidade, algumas 
ainda em discussão, outras já aprovadas, implantadas ou em fase de implantação. Comum a essas reformas está o propósito aparente de mudar o Judiciário para torná-lo mais ágil, transparente, democrático, justo, "moderno". Uma modernidade às vezes tardia, em épocas de pós-modernidade, mas mesmo assim bem-vinda.

Já se somam às dezenas mudanças no sistema judiciário brasileiro, entre elas aquelas determinadas pela Emenda Constitucional n. 45, várias alterações na legislação processual buscando principalmente a celeridade da Justiça, e algumas iniciativas voltadas à modernização da gestão de órgãos do Judiciário. As discussões em torno de mudanças no sistema judiciário são complexas, afetam a todos, envolvem vários órgãos, múltiplos e diversos interesses, implicam definiç̧ões acerca do papel de cada poder na realização do Estado Democrático de Direito. Para que ocorram, dependem de alguma legitimação social e exigem um determinado consenso entre os membros dos três poderes, normalmente só alcançado em torno de idéias gerais como eficiência, modernização, democratização etc.

O Poder Judiciário no Brasil ainda carece de um planejamento próprio que o contextualize, esclareça seu foco, objetivos e metas a serem alcançadas. Ao contrário, o que se verifica são iniciativas, mais ou menos fundamentadas, partindo dos poderes do Estado, da sociedade civil organizada ou de grupos que defendem interesses específicos para a atuação do Judiciário. A falta de uma ação coordenada faz com que se percam energia, tempo, dinheiro e esperança na solução de problemas que possam fortalecer o Judiciário perante a sociedade brasileira.
A falta de planejamento, contudo, não significa necessariamente incapacidade para pensá-lo, podendo refletir a ausência de um consenso mínimo em torno das mudanças ou mesmo o desinteresse em modificar determinado estado de coisas. Seja como for, a ausência de planejamento e metas, e a indefinição quanto a ações de curto, médio e longo prazo, colabora para a manutenção do statu quo e dificulta a construção de um Judiciário socioambientalmente responsável, uma vez que sequer discute as premissas nas quais o mesmo estaria assentado.

Se, de um lado, há indefinição, de outro a própria Constituição já fixou os objetivos e metas para a sociedade brasileira, e esses são os pontos que devem nortear o planejamento e as ações para a efetiva reforma do Judiciário. Por determinação constitucional, o Brasil é um Estado Democrático, fundado na dignidade da pessoa humana, que objetiva a construção de uma sociedade livre, justa e solidária, em um ambiente ecologicamente equilibrado, preservado para as presentes e futuras gerações. A concretização deste modelo deve orientar o comportamento do poder público e dos particulares. Não é outro o rumo apontado por Marcio Santilli quando afirma:

o socioambientalismo é um invenção brasileira, sem paralelo no ambientalismo internacional, que indica precisamente o rumo de integrar políticas setoriais, suas perspectivas e atores, num projeto de Brasil que tenha sua cara e possa, por isso mesmo, ser politicamente sustentado. (SANTILLI, 2008)

A atuação do Judiciário para a defesa e proteção dos direitos socioambientais deixa neste contexto de ser apenas uma questão política para tornar-se um dever deste Poder 
com toda a sociedade brasileira, e é neste quadro que deve inserir-se a preocupação com as reformas do Poder Judiciário no Brasil.

Aconcretização de direitos socioambientais não depende apenas de boa vontade, mas de planejamento integrado voltado à sua realização e opções claras para as quais a Constituição apresenta base legal. A tarefa é mais difícil porque a concretização de direitos socioambientais contraria a lógica jurídica dominante no delineamento dos conflitos socioambientais. Vejamos:

A sociedade ainda acredita que desenvolvimento e crescimento econômico têm a mesma raiz, enquanto o socioambientalismo desvincula os dois conceitos, relacionando desenvolvimento à distribuição de riquezas e a realização da justiça social.

Os conflitos jurídicos são privadamente tratados pelo direito e sua solução está assentada em uma lógica patrimonial. Os direitos socioambientais não são apropriados a um patrimônio individual porque são bens que aproveitam a toda sociedade e tampouco podem ser valorados economicamente.

Os bens socioambientais podem ser materiais ou imateriais, tangíveis ou intangíveis, enquanto a dogmática tradicional protege bens materiais tangíveis, sendo ainda bastante raros a proteção de bens imateriais, mas mesmo nesses casos a resposta jurídica depende de uma valoração econômica.

O socioambientalismo sustenta que a função socioambiental da propriedade deve condicioná-la, ao contrário da dogmática tradicional que ainda vê a propriedade como um direito privado, restringível por sua função social.
A Constituição reconhece e tutela de direitos difusos, coletivos ou individuais, mas restringe a legitimidade para a ação em proteção dos bens socioambientais, assim como refuta a possibilidade de a natureza ser ela, mesmo, sujeito de direitos, proposta que vem sendo discutida pela primeira vez na constituinte equatoriana.

\subsection{Propostas para um Judiciário Sustentável}

O socioambientalismo pressupõe a quebra de um paradigma de desenvolvimento, hegemônico nas sociedades ocidentais modernas, e propugna por um novo modelo mais próximo do que se vem denominando desenvolvimento sustentável, embora ambos partam de premissas distintas: enquanto o desenvolvimento sustentável acredita ser possível manter o padrão de crescimento e distribuí-lo aos países mais pobres, os quais teriam um piso de consumo material que lhes garantiria progressivamente o alcance da cidadania, o socioambientalismo propõe uma ruptura com o modelo que associa desenvolvimento a crescimento e considera que a sociedade socioambientalmente responsável depende de que se estabeleçam outras relações fora do padrão de consumo vigente, que garantam a proteção da natureza, a manutenção e recuperação dos recursos naturais, e a revisão do conceito de propriedade.

Neste contexto, a sociedade socioambientalmente responsável impõe reformas ao Poder Judiciário definidas por um planejamento que contemple preocupações socioambientais, para que se possa caminhar na direção de sua concretização. Essas 
propostas estão em consonância com um ou várias das dimensões do ecodesenvolvimento, conforme defendido por Ignacy Sachs, e consistem no seguinte:

a. planejamento de curto, médio e longo prazo, fixação de objetivos, estabelecimento de metas, definição de ações e avaliação contínua de seu cumprimento, em consonância com as propostas socioambientais;

b. prioridade na realização de políticas pública, as quais condicionam os interesses privados;

c. atenção a diferentes conceitos de justiça e busca da justiça social;

d. proteção ambiental e preservação dos recursos naturais;

e. reconhecimento e tutela de bens não valoráveis economicamente;

f. ênfase na proteção de direitos coletivos indivisíveis;

g. prioridade à função social e pública da propriedade quando em oposição ao interesse privado existente sobre ela;

h. reconhecimento do pluralismo jurídico;

i. fortalecimento de uma democracia que ultrapassa os valores básicos da representativa e das regras da maioria;

j. defesa do juiz ativo, não pelo ativismo em si, mas pela obrigação que tem de obrigar a realização de políticas públicas "saudáveis" e determinar a realização de políticas sociais, em detrimento do atendimento a interesses individuais;

k. prioridade no combate à corrupção e aos crimes de colarinho branco porque esses fazem ruir a democracia e a base do Estado de Direito.

Esses são os parâmetros que devem nortear uma reforma do Judiciário, capazes de torná-lo apto a enfrentar os desafios de uma sociedade socioambientalmente responsável e solidária. Seu desenvolvimento e implementação depende das condições políticas, sociais e econômicas em cada Estado, mas essas diretrizes devem ser mantidas, como forma de alcançar um Judiciário apto a enfrentar os desafios impostos pela sociedade agora pulsante.

\section{CONSIDERAÇÕES FINAIS}

A noção hegemônica de desenvolvimento vinculado ao fator crescimento econômico vem sendo questionada pelo chamado desenvolvimento sustentável. O desenvolvimento sustentável reúne prioritariamente as dimensões social e econômica da sustentabilidade, embora não exclua as demais dimensões. O socioambientalismo pressupõe a sustentabilidade e propugna por um novo modo de organização social que questiona alguns dos postulados do desenvolvimento sustentável, especialmente o padrão de consumo, a forma de proteção e titularidade dos recursos naturais e a noção de propriedade, em seus diferentes aspectos.

A determinação constitucional de busca de uma sociedade digna, justa e solidária impõe ao poder público o dever de realizar políticas públicas e ações voltadas à sua concretização. O Judiciário tem um importante papel a cumprir na efetivação deste novo 
modelo de sociedade, mas para que possa assumir esse papel deve priorizar em sua reforma mecanismos que levem em conta pelo menos alguns dos seguintes aspectos: considerações de diferentes concepções de justiça e busca da justiça social; proteção ambiental e preservação dos recursos naturais; efetividade dos direitos humanos; reconhecimento e proteção de bens não suscetíveis de valor econômico; ênfase na proteção dos direitos coletivos indivisíveis; prioridade à função social e pública da propriedade quando em oposição ao interesse privado existente sobre ela; reconhecimento e afirmação do pluralismo jurídico; fortalecimento de uma democracia que ultrapasse os valores básicos da concepção representativa; defesa do juiz ativo, não pelo ativismo em si mesmo, mas pela obrigação que tem de exigir a realização de políticas públicas saudáveis e determinar a realização de políticas sociais; prioridade no combate à corrupção e aos crimes protegidos pela impunidade dos grupos privilegiados, porque estes colocam em risco a democracia e o estado de direito. Estas são as condições para que o Poder Judiciário assuma o protagonismo que a sociedade brasileira lhe exige, na consecução de uma sociedade mais solidária, digna e justa.

\section{REFERÊNCIAS}

MEADOWS, Dennis L., MEADOWS, Donella H., RANDERS, J. \& BEHRENS, William W. Limites do crescimento - um relatório para o Projeto do Clube de Roma sobre o dilema da humanidade. São Paulo: Ed. Perspectiva, 1973.

BAUMAN, Zigmut. Modernidade Líquida. São Paulo: Jorge Zahar Editor, 2001
BECK, Ulrich. Risk society: Towards a new modernity. Londres: Sage Publications, 1992.

CAVALCANTI, Clóvis (Org.). Desenvolvimento e natureza: estudos para uma sociedade sustentável. São Paulo: Cortez Editora, 1995.

CAVEDON, Fernanda de Salles. VIEIRA, Ricardo Stanziola. Socioambientalismo e justiça ambiental como paradigma para o sistema jurídico-ambiental: estratégia de proteção da sóciobiodiversidade no tratamento dos conflitos jurídico-ambientais. In: Âmbito Jurídico, Rio Grande, 40, 30/04/2007 [Internet]. Disponível em: <http://www.ambitojuridico. com.br/site/index.php?n_link=revista_artigos_ leitura\&artigo_id=1736>. Acesso em 26/06/2008.

GIDDENS, Anthony; BECK, Ulrich; LASH, Scott. Modernização reflexiva: política, tradião e estética na ordem social moderna. São Paulo: Editora da Universidade Estadual Paulista, 1997.

INSTITUTO SOCIOAMBIENTAL. Almanaque Brasil Socioambiental. São Paulo: Instituto Socioambiental, 2004.

IANNI, Octavio. A sociedade global. 5. ed. Rio de Janeiro: Civilização Brasileira, 1997.

LAYRARGUES, Philippe Pomier. Do ecodesenvolvimento ao desenvolvimento sustentável: evolução de um conceito. In: Proposta. Rio de Janeiro: FASE, ${ }^{\circ} 71$, p. 5- 10, 1997.

LYOTARD, Jean-François. A condição pósmoderna. 5. ed. Rio de Janeiro: José Olympio, 1998. 132p.

MARÉS, Carlos Frederico. Introdução ao Direito Socioambiental. Em LIMA, André (Org.). $O$ Direito para o Brasil Socioambiental. Porto Alegre: Sérgio Antônio Fabris Editor, 2002.

MARTINS, Tais. O conceito de desenvolvimento sustentável e seu contexto histórico: algumas considerações. Jus Navigandi, Teresina, ano 8, n. 382, 24 jul. 2004. Disponível em: <http://jus2.uol.com.br/doutrina/ texto.asp?id=5490>. Acesso em: 26 jun. 2008. 
WCED, Our Common Future. World

Commission on Environment and Development, Oxford: Oxford, University Press, 1987.

SACHS, Ignacy. Ecodesenvolvimento: crescer sem destruir. São Paulo: Vértice, 1986.

SANTILLI, Juliana. Socioambientalismo e novos direitos: proteção jurídica à diversidade biológica e cultural. São Paulo, Petrópolis, 2005.

SANTILLI, Márcio. "Transversalidade” na corda bamba. Disponível em http://www. socioambiental.org/esp/novogov/index.shtm. Acessado em 26 de junho de 2008.
SILVA JÚNIOR, Ivanaldo Soares da. Do desenvolvimento humano ao desenvolvimento sustentável: análise dos conteúdos jurídicos e filosóficos dos conceitos do direito ao desenvolvimento e do direito do desenvolvimento.. Jus Navigandi, Teresina, ano 6, n. 53, jan. 2002. Disponível em: <http://jus2. uol.com.br/doutrina/texto.asp?id=2493>. Acesso em: 26 jun. 2008.

SOUZA SANTOS, Boaventura de. Pela mão de Alice: o social e o político na pós-modernidade. 10. ed. São Paulo, Cortez, 2005.

http://www.deepecology.org/movement.htm 